inconsistent and erratic supply of insulin. Because insulin dependence in diabetes implies lifelong dependence, a regular and consistent supply of insulin is needed. The International Diabetes Federation has always advocated that insulin should be freely available to all those who need it, while a recently published report from a World Health Organisation study group states: "In all countries, the availability of insulin as an essential life-saving drug should be ensured, without imposition of taxes or restrictions regarding the transfer of technology for its manufacture." 7

Problems with the supply of insulin in the developing world have been reported anecdotally for many years. Recently three reports have highlighted the problem. In one McLarty et al distributed a questionnaire in Africa through two journals 8 ; Savage did the same through Equipment Charity Hospitals Overseas (ECHO). ${ }^{9}$ In the third, the International Diabetes Federation sent a questionnaire to its 105 member associations in 85 countries. ${ }^{10}$ All came to the same conclusions: that in many countries insulin supplies were erratic and often not available to people with insulin dependent diabetes mellitus. McLarty et al received replies from 50 practitioners working in 25 African countries. Most commented that insulin was rarely available in rural areas. Only $36 \%$ believed that insulin was available sometimes in small towns, and half reported that insulin was sometimes unavailable in large urban centres. Even when it was available in some cities most patients could not afford it. Insulin was unavailable for at least some of the time in $22 \%$ of countries and was free in only two thirds of the countries.

The costs of insulin varied widely around the world; one phial cost from $\$ 2.70$ to $\$ 22$ (£1.80 to $£ 15)$. The cheapest supplies were not necessarily available in the poorest countries. In Tanzania, for example, where patients may need to buy insulin, it can cost $\$ 15(£ 10)$ per phial-equivalent to one month's pay for many people. To this must be added the cost of syringes and monitoring materials, which are often not available. Colleagues and I have calculated that the annual cost of insulin alone for sub-Saharan Africa, excluding South Africa, is roughly $\$ 25 \mathrm{~m}(£ 16 \mathrm{~m})$, on the basis of Tanzanian estimates of $\$ 156(£ 104)$ per patient. ${ }^{8}$

Diabetes tends to be ignored in the face of major disasters such as famine, drought, and genocide, but people with insulin dependent diabetes mellitus have a right to life; and at a relatively small cost per patient by Western standards many more could have a productive life-and, indeed, could live.
The situation has been worsened by the policies of the International Monetary Fund and World Bank, which are attempting to ensure that health care systems stay within their very limited budget and that patients contribute to costs of care. This is clearly impossible for people with diabetes in the poorest countries. Some countries-for example, Bangladesh - are strikingly successful in ensuring that insulin is available for all, but this is the exception.

In parallel, an unofficial group working out of Melbourne under the umbrella of the International Diabetes Federation has been instrumental in providing insulin for emergency use in several countries, particularly in Africa; but should we have to rely on charitable donations for such a fundamental drug? Industry could help by charging less for insulin in the poorest countries, but it fears that this would lead to re-export to Western countries and large mark ups by unscrupulous middle men. Recently a man was arrested at Cairo airport attempting to smuggle out 500000 doses of insulin, purchased at a highly subsidised price, to resell abroad. ${ }^{11}$ In the end it is the responsibility of governments to ensure that drugs such as insulin are available for those who need them. And it is up to the diabetic community and health care professionals to ensure that this comes about.

K G M M ALBERTI

Department of Medicine,

Professor of medicine

Medical School,

University of Newcastle,

Newcastle upon Tyne NE2 4HH

Professor Alberti does occasional consultancies for insulin manufacturers and his department receives grants from them.

1 Dorman JS, LaPorte RE. Mortality in insulin-dependent diabetes. In: National Diabetes Data Group. Diabetes in America. Bethesda, MD: National Institute of Health, 1985. (NIH publication 85-1468 XXX-1 to XXX-9).

2 Diabetes Control and Complications Trial Research Group. The effect of intensive treatment of diabetes on the development and progression of long term complications in insulin of diabetes on the development and progression of long term
dependent diabetes mellitus. $N$ Engl F Med 1993;329:977-86.

3 Swai ABM, Lutale JK, McLarty DG. Prospective study of incidence of juvenile diabetes mellitus over 10 years in Dar es Salaam, Tanzania. BMF 1993;306:1570-2.

4 Elamin A, Omer MIA, Zein K, Tuvemo T. Epidemiology of childhood type I diabetes in Sudan 1987-1990. Diabetes Care 1992;15:1556-9.

5 McLarty DG, Kinabo L, Swai ABM. Diabetes in tropical Africa: a prospective study, 1981-7. Il. Course and prognosis. BMF 1990;300:1107-10.

6 Joslin EP. The treatment of diabetes mellitus. 4th ed. Philadelphia: Lea and Febiger, 1928:384.

7 World Health Organisation Study Group. Prevention of diabetes mellitus. WHO Tech Rep Ser $1994 ;$ No.844.

8 McLarty DG, Swai ABM, Alberti KGMM. Insulin availability in Africa: an insoluble problem. International Diabetes Digest 1993;5:15-7.

Savage A. The insulin dilemma: a survey of insulin treatment in the tropics. Internationa Diabetes Digest 1994;5:19-20.

10 Deeb LC, Tan MH, Alberti KGMM. Insulin availability among International Diabetes Federation member associations. Diabetes Care 1994;17:220-3.

11 Cash injection. The Guardian Aug 29,1994:6.

\title{
Understanding clinical trials
}

\section{What measures of efficacy should journal articles provide busy clinicians?}

The randomised clinical trial has revolutionised the way that we decide whether a treatment or intervention does more good than harm. In its breadth and explanatory power it provides a cornerstone not only for evidence based medicine ${ }^{1}$ but for evidence based public health, evidence based hospital administration, evidence based purchasing, and evidence based consumerism.

Randomised trials provide not only qualitative conclusions about whether a treatment is better but also quantitative estimates of the extent to which it is better. Take as an example (with rounded numbers) an overview of the effects of treatment with antihypertensive drugs on patients with moderate to severe hypertension. Trials have shown that about 1800 strokes occur among 15000 patients randomised to active drugs for an average of five years, while about 3000 such events occur in 15000 randomised to placebo or no active treatment. ${ }^{2}$ This difference in stroke is extremely unlikely to be due to chance (in other words it is highly significant statistically), providing the qualitative answer that antihypertensive drugs are better than no treatment for patients with moderate to severe hypertension. 
These results also tell us a lot about how much better drug treatment is, but the way in which this quantitative difference is expressed can lead clinicians to different conclusions about whom to treat-whether as individual patients or entire populations. The most recent example of this confusion appears in this issue ( $p$ 761), ${ }^{3}$ and others have been reported previously. ${ }^{4-9}$ Their explanation and prevention require a brief review of some of the available measures of efficacy.

Going back to the hypertension studies, efficacy could be expressed in terms of the relative probabilities of stroke with treatment $(1800 / 15000=0 \cdot 12)$ and without it $(3000 / 15000=0 \cdot 20)$, either as a simple risk ratio $(0 \cdot 12 / 0 \cdot 20=0 \cdot 6)$ or, as commonly appears in the reports of randomised trials, as the complement of the risk ratio expressed as a percentage $(1-0 \cdot 6) \times 100=40 \%)$ and called the relative risk reduction-antihypertensive drugs thus seem to cut the risk of stroke in such patients by about $40 \%$. A second measure similar to the risk ratio but possessing some more attractive statistical properties expresses this relative difference in terms of the relative odds of stroke with treatment $(1800: 13200=0 \cdot 14$ to 1$)$ and without it ( $3000: 12000=0 \cdot 25$ to 1$)$ and generates an odds ratio $(0 \cdot 14 / 0 \cdot 25=0 \cdot 56)$. Foreign to most clinicians, the odds ratio is better discussed elsewhere. ${ }^{10}$

Yet another way of telling us how much better antihypertensive drugs are for such patients contrasts our estimates of the absolute probabilities of stroke with $(0 \cdot 12)$ and without $(0 \cdot 20)$ active treatment and expresses their arithmetic difference $(0 \cdot 20-0 \cdot 12=0 \cdot 08)$ in an expression called the absolute risk reduction. Most clinicians are not comfortable with the concept of absolute correct reduction risk, but it achieves both clarity and more appeal when expressed as its reciprocal $(1 / 0 \cdot 08=13)$, for that describes the number of patients who need to be treated to prevent one event-in this case, the number of hypertensive patients one needs to treat with antihypertensive drugs for five years to prevent one stroke.

The big clinical advantage of the "number needed to be treated" is seen when we examine these measures among a second set of patients, this time with less severe hypertension. Their risk of stroke even if they remain untreated (that is, their baseline susceptibility) is much lower than the risks in the first examples. Over five years, strokes occurred in about 135 of 15000 , or 0.009 , of these lower risk patients receiving active treatment and in 225 of 15000 , or 0.015 , or those receiving placebo or no treatment.

The lower susceptibility to stroke of these patients with milder hypertension is reflected in the soaring number who would need to be treated: $1 /(0 \cdot 015-0 \cdot 009)=167$. This quite large number of patients needs to be treated for five years for a doctor to be able to expect to prevent a single strokemore than 10 times the number of patients with more severe hypertension who need to be treated to achieve the same goal. But the relative risk reduction is the same as before $(1-0.009 / 0.015) \times 100=40 \%)$. This apparent paradox arises because the "number needed to be treated" includes, but the relative risk reduction excludes, information about patients' susceptibility to the events being prevented. Relative risk reductions can remain high (and thus make treatments seem attractive) even when susceptibility to the events being prevented is low (and the corresponding numbers needed to be treated are large). As a result, restricting the reporting of efficacy to just relative risk reductions can lead to greater-and at times excessive- zeal in decisions about treatment for patients with low susceptibilities.

Empirical evidence has been produced to support this theoretical concern. In both North America and Europe clinicians have been presented with the results of the same randomised trials in different ways. They mostly expressed greater confidence in, and a greater likelihood to initiate, treatments when their efficacy was expressed as the relative risk reduction; conversely, they reported lower confidence in, and a lower likelihood to initiate, these same treatments when their efficacy was expressed in absolute terms such as the number of patients who would need to be treated. Moreover, these discrepancies were exaggerated when susceptibility was low - a circumstance that often faces a clinician who attempts to extrapolate the results of a trial performed among highly susceptible patients to a more usual clinical settings. ${ }^{11}$ The authors or most of these studies concluded that the clinical decisions based on the number of patients who would need to be treated were the more sensible.

So when a journal publishes reports of individual trials or systematic reviews of several trials what measures of efficacy should be included for busy clinicians? Ideally, the information provided should go far beyond efficacy to include measures of harm as well as benefit, to integrate patients' views on their quality of life with and without treatment, and to include the economic consequences of the treatment alternatives. But when such analyses have not been done and the only data available are on efficacy, busy clinical readers deserve three sorts of information (complete with their confidence intervals): at least one absolute measure of efficacy (such as the number of patients who would need to be treated to prevent one event), the susceptibility of control patients to the target outcome (as a starting point for extrapolation to their own patients ${ }^{12}$ ), and (though they could calculate it from the former two) some relative measure of efficacy (such as the relative risk reduction).

DAVID L SACKETT

Nuffield Department of Clinical Medicine,

Professor of clinical epidemiology

University of Oxford,

Oxford

RICHARD J COOK Research assistant professor

Department of Statistics and Actuarial Science,

University of Waterloo,

Waterloo, Ontario,

Canada

1 Evidence-based Medicine Working Group. Evidence-based medicine; a new approach to teaching the practice of medicine. $f A M A$ 1992;268:2420-5.

2 Collins R, Peto R, MacMahon S, Hebert P, Fiebach NH, Eberlein KA, et al. Blood pressure, stroke, and coronary heart disease. Part 2. Short-term reductions in blood pressure: stroke, and coronary heart disease. Part 2. Short-term reductions in blood pressure:
overview of randomized drug trials in their epidemiologic context. Lancet 1990;335:827-38. 3 Bucher HC, Weinbacher M, Gyr K. Influence of method of reporting study results on decision of physicians to prescribe drugs to lower cholesterol concentration. BMF 1994;309: 761-4

4 Laupacis A, Sackett DL, Roberts RS. Therapeutic priorities of Canadian internists. Can Med Assoc F 1990;142:329-33.

5 Naylor CD, Chen E, Strauss B. Measured enthusiasm: does the method of reporting trial results alter perceptions of therapeutic effectiveness? Ann Intern Med 1992;117:916-21.

Forrow L, Taylor WC, Arnold RM. Absolutely relative: how research results are summarized can affect treatment decisions. Am $\mathcal{F}$ Med 1992;92:121-4.

7 Malenka DJ, Baron JA, Johansen S, Wahrenberger JW, Ross JM. The framing effect of relative and absolute risk. $\mathcal{F}$ Gen Intern Med 1993;8:543-8.

8 Farkouh ME, Sauve JS, Kassam H, Lee HN, Sackett DL. Varying formats in which trial results are reported can affect clinical decision making. Clin Res 1993;41:517A

9 Bobbio M, Demichells B, Glustetto G. Completeness of reporting trial results: effect on physicians' willingness to prescribe. Lancet 1994;343:1209-11.

10 Sinclair JC, Bracken MB. Clinically useful measures of effect in binary analyses of randomized Sinclair JC, Bracken MB. Clinically usefu
trials. F Clin Epidemiol 1994;87:881-9.

11 Guyatt GH, Sackett DL, Cook DJ for the Evidence-Based Medicine Working Group. Users' guides to the medical literature. II. How to use an article about therapy prevention. B. What were the results and will they help me in caring for my patients? $\mathscr{F} A M A$ 1994;271:59-63.

12 Cook RJ, Sackett DL, Cook DJ. Improving the usefulness of the NNT at the bedside. $f$ Gen Intern Med 1994;9:27. 